\title{
Gallium Ga 68 PSMA-R2
}

National Cancer Institute

\section{Source}

National Cancer Institute. Gallium Ga 68 PSMA-R2. NCI Thesaurus. Code C154382.

A radioconjug ate composed of PSMA-R2, a human prostate-specific membrane antigen (PSMA)-targeting ligand, conjugated to the beta-emitting radioisotope gallium Ga 68, with potential imaging activity during positron emission topography/computed tomography (PET/CT). Upon administration of gallium Ga 68 PSMA-R2, the PSMA-R2 moiety targets and binds to PSMA-expressing tumor cells. This allows for visualization of PSMA-expressing cells upon imaging. PSMA, a tumor-associated antigen (TAA) and type II transmembrane protein, is expressed on the membrane of prostatic epithelial cells and overexpressed on the majority of prostate tumor cells. 